Research Article/Araştırma Makalesi

\title{
Developing an Attitude Scale for Three-Dimensional Modeling and 3D Modeling Course: A Validity and Reliability Study
}

\author{
Ali İhsan BENZER* 1 (D) Bünyamin YILDIZ ${ }^{2}$ \\ ${ }^{1}$ Hatay Mustafa Kemal University, Department of Management Information Systems, Hatay, Turkey, aibenzer@gmail.com \\ ${ }^{2}$ Hatay Mustafa Kemal University, Department of Mathematics, Hatay, Turkey, byildiz@mku.edu.tr \\ * Corresponding Author: aibenzer@gmail.com
}

\begin{tabular}{|c|c|}
\hline Article Info & Abstract \\
\hline $\begin{array}{l}\text { Keywords: Attitude, scale } \\
\text { three-dimensional } \\
\text { modeling, university students, } \\
\text { validity and reliability } \\
\text { doi 10.18009/jcer.749364 } \\
\text { Publication Language: Turkish }\end{array}$ & $\begin{array}{l}\text { The aim of this research was to develop a valid and reliable } \\
\text { measurement instrument to explore attitudes of university students } \\
\text { towards three-dimensional modeling and the course about it. The } \\
\text { measurement instrument was designed as a 5-point Likert scale. A total } \\
\text { of } 204 \text { university students took part in the research on the condition } \\
\text { that they took courses on 3D modeling. On the data collected during } \\
\text { the implementation, factor analysis was performed with varimax } \\
\text { rotation technique of principal analysis methods. The factor analysis } \\
\text { yielded three different factors which could explain } 54 \% \text { of the total } \\
\text { variance under a total of } 30 \text { items. The resulting factors were named as } \\
\text { "Importance", "Interest" and "Anxiety" by cause of the respective } \\
\text { contents of the items under each factor. The reliability coefficient of the } \\
\text { entire scale was calculated as } 0.94 \text {. The same value was found to be } \\
0.90,0.91 \text { and } 0.82 \text { for each of the separate factors, respectively. }\end{array}$ \\
\hline CrossMark CC & $\begin{array}{l}\text { To cite this article: Benzer, A. İ. \& Yıldız, B. (2020). } 3 \text { boyutlu } \\
\text { modelleme ve dersine yönelik tutum ölçeği: Geçerlik ve güvenirlik } \\
\text { çalışması. Journal of Computer and Education Research, } 8 \text { (16), 688-704. } \\
\text { DOI: } 10.18009 \text { /icer. } 749364\end{array}$ \\
\hline
\end{tabular}

\section{Boyutlu Modelleme ve Dersine Yönelik Tutum Ölçeği: Geçerlik ve Güvenirlik Çalışması}

\begin{tabular}{|c|c|}
\hline Makale Bilgisi & $\ddot{\mathrm{O} z}$ \\
\hline 8 Haziran 2020 & $\begin{array}{l}\mathrm{Bu} \text { araştırmanın amacı, üniversite öğrencilerinin } 3 \text { boyutlu } \\
\text { modellemeye ve bununla ilgili derse yönelik tutumlarını incelemek icin }\end{array}$ \\
\hline 8 A $\breve{g}$ ustos 2020 & \\
\hline $\begin{array}{l}\text { Anahtar kelimeler: } 3 \text { boyutlu } \\
\text { modelleme, geçerlik ve güvenirlik, } \\
\text { ölçek geliştirme, tutum, üniversite } \\
\text { öğrencileri }\end{array}$ & $\begin{array}{l}\text { tipinde geliştirilmiştir. Araştırmaya, } 3 \text { boyutlu modelleme ile ilgili ders } \\
\text { almış toplam } 204 \text { üniversite öğrencisi katılmıştır. Toplanan veriler } \\
\text { üzerinde temel bileşen analizi yöntemi/varimax döndürme tekniği ile } \\
\text { faktör analizi yapılmıştır. Faktör analizi sonucunda, } 30 \text { maddeden } \\
\text { oluşan toplam varyansın \% 54'ünü açıklayan, üç faktörden oluşan bir } \\
\text { ölçek elde edilmiştir. Ölçeği oluşturan faktörlere, içerdikleri maddelerin }\end{array}$ \\
\hline doi $10.18009 /$ jcer.749364 & $\begin{array}{l}\text { içerikleri ile uyumlu olacak şekilde sırasıyla "Önem", "İlgi" ve "Kaygı" } \\
\text { isimleri verilmiştir. Ölçeğin faktör analizi gerçekleştirildikten sonra } \\
\text { ölçeğin tamamı ve her bir faktör için ayrı ayrı güvenirlik katsayısı }\end{array}$ \\
\hline Yayım Dili: Türkçe & $\begin{array}{l}\text { hesaplanmıştır. Ölçeğin tamamı için güvenirlik katsayısı 0,94 olarak } \\
\text { bulunmuştur. Ölçeği oluşturan “Önem”, “İlgi” ve “Kaygı” faktörlerine } \\
\text { ait güvenirlik katsayıları sırasıyla 0,90, } 0,91 \text { ve } 0,82 \text { olarak bulunmuştur. }\end{array}$ \\
\hline
\end{tabular}




\section{Summary}

\section{Developing an Attitude Scale for Three-Dimensional Modeling and 3D Modeling Course: A Validity and Reliability Study}

\section{Introduction}

Many countries are working to integrate innovative technologies into educational settings with the purpose of teaching the 21st century skills to their students. One of the innovative technologies of our time is computer-aided three-dimensional modeling technology. Today, with the effect of developments in computer hardware and software, computer-aided three-dimensional modeling technologies are seen and used in many areas (Yue, 2008). Such technologies are the most widely used in settings of the film-making, advertising, medicine, industry, engineering, architecture, computer games, and culture and education (O'Malley, 2015).

The widespread use of three-dimensional modeling technology leads to extensive use of three-dimensional modeling training at the same time. Particularly, as a result of the developments in informatics since 1980s, courses on computer-aided design and modeling are being integrated into curricula of engineering (Yue, 2008) and architecture (Varinlioğlu, Alaçam, Başarır, Genca, \& Üçok, 2016). Besides this, the use and teaching of software concerning three-dimensional modeling is gaining an important place in innovative learning environments such as STEM and the Maker movement, which are being more and more popular lately (Bull, Chiu, Berry, Lipson, \& Xie, 2014; Taylor, 2016). In Turkey, like most of the other countries, this issue is assuming greater importance and thus studies are underway to give training and courses related to three-dimensional modeling in higher education institutions. For example, the curricula of teaching programs were revised by the Council of Higher Education (CoHE) in 2018, and a course titled "Modeling and Design in Education" was introduced to the curriculum of "Computer and Instructional Technologies" program (YÖK, 2018). Another one was again undertaken by the CoHE in the form of updating the university preference guidelines in 2019 (YÖK, 2019). As a result of the study, the Higher Education Council nominated "3D modeling and animation" as one of the professions of the 
occupations of the future and launched acceptance of students to associate degree programs in this area in 2019.

Examination of learner attitudes is one of the research topics that are frequently discussed in educational studies. Previous research indicates a meaningful positive relationship between students' attitudes towards a course and their achievement in that course (Bakar et al., 2010; Birgin \& Demirkan, 2017; Nicolaidou \& Philippou, 2003; Peker \& Mirasyedioğlu, 2003; Yenilmez \& Özabac1, 2003; Yücel \& Koç, 2011). It is reported in the literature that students' attitude towards a course is one of the most important factors affecting their success in that course (Ekici, 2002; Singh, Granville, \& Dika, 2002; Ünal, Yilmaz, \& Kardeş, 2019). Therefore, it seems essential to study students' attitudes towards school lessons or instruction in order to realize an effective and efficient teaching (Birgin \& Küçük, 2012; Yeşilyurt \& Gül, 2009). This can be achieved only if instruments of measurement are available with completed validity and reliability checks. However, on the specific topic of learners' attitude regarding three-dimensional modeling and design, no valid and reliable instrument of measurement was found in the literature. In the current research, it was thus aimed to close the research gap. The aim of this study was to develop a valid and reliable measurement instrument to find out university students' attitudes towards three-dimensional modeling and course. It is thus thought to expand the national and international literature about the topic.

\section{Method}

The research was carried out with survey method because the purpose of survey model is to describe a situation as it is. Surveys are carried out with an eye to depict the individual or object under examination as it is (Karasar, 2016). The sample in this research consisted of 204 university students who took courses on three-dimensional modeling during their undergraduate study or associate degree program as applicable. The students participated on voluntary basis. $57 \%$ of them were males and $43 \%$ were females. In this research, an attitude scale was developed by the researchers to explore attitudes of the participants towards three-dimensional modeling as a concept and courses on threedimensional modeling. The measurement instrument was designed as a 5-point Likert scale ranging as "Strongly Agree", "Agree", "Undecided", "Disagree" and "Strongly Disagree" to identify respondents' attitudes. Straight items were graded from 5 to 1 where the lowest 
score corresponded to "Strongly Disagree", but reverse items were graded between 1 and 5 with the opposite grades for the statements. For the validity and reliability check of the scale, exploratory factor analysis (EFA) was performed on the data collected by using varimax rotation technique as a method of principal component analysis. The reliability coefficient of the scale was calculated. In addition, confirmatory factor analysis (CFA) was carried out regarding the obtained structure.

\section{Results}

Before performing EFA, Kaiser-Meyer-Olkin (KMO) and Bartlett Sphericity coefficients were calculated to check the suitability of the data. It was found the KMO test coefficient was calculated as 0.917 and the Bartlett Sphericity test was found to be significant. As a result of EFA analysis, a three-factor scale was obtained with 30 items which explain $54 \%$ of the total variance. The resulting factors were named as "Importance", "Interest" and "Anxiety" by cause of the respective contents of the items under each factor. The factors included 11, 14 and 5 items, respectively. The scale included 16 straight and 14 reverse items. The factor load values of the items in the scale vary from 0.46 to 0.80 . When it comes to the item analysis, independent samples t-test was applied to total scores obtained from the groups that were $27 \%$ below and above the total scores. It was found out that all items in our scale can distinguish respondents' attitudes significantly. The scale as a whole provided a reliability coefficient of 0.94 conferring reliability coefficients to the factors as 0.90, 0.91 and 0.82. CFA was performed to verify the model after EFA. In this study, Chi-Square $(\chi 2) / d f$, SRMR, GFI, AGFI, RMSEA and CFI fit indices were calculated. Fit indices indicated the suitability of the three-factor structure. According to the analysis results, it can be said that the scale is a valid and reliable measurement tool. 


\section{Giriş}

Ülkeler, uluslararası alanda rekabet etme güçlerini artırabilmek için çağın gerektirdiği becerilerle donanmış nitelikli bireyler yetiştirmeye çalışmaktadırlar. Teknoloji uygun öğretim yöntemleriyle sunulduğunda, 21. yüzyıl becerilerinin kazandırılmasında hem eğitimcilere ve hem de öğrencilere önemli fırsatlar sunabilmektedir. Bu nedenle birçok ülke 21. yüzyıl becerilerini öğrencilerine kazandırmak amacıyla yenilikçi teknolojileri eğitimöğretim ortamlarına entegre etmek için çalışmalar yapmaktadır.

Günümüzün yenilikçi teknolojilerinden biri de bilgisayar destekli 3 boyutlu modelleme teknolojisidir. 3 boyutlu modelleme, özel yazılımlar aracılığıyla 3 boyutlu bir nesnenin matematiksel gösteriminin geliştirilmesi sürecidir ve bu süreç sonunda ortaya çıan ürün ise 3 boyutlu model olarak adlandırılır (Spallone, 2015). Günümüzde, bilgisayar donanımı ve yazılımı alanlarında yaşanan gelişmelerin sonucunda bilgisayar destekli 3 boyutlu modelleme teknolojileri birçok alanda kullanılmaya başlanmıştır (Yue, 2008). Sinema, reklamcılık, tıp, endüstri, mühendislik, mimarlık, bilgisayar oyunları, kültür ve eğitim, 3 boyutlu modelleme teknolojisinin yaygın olarak kullanıldığı başlıca alanlardır (O'Malley, 2015). Eğitim alanında yapılan araştırmalar incelendiğinde 3 boyutlu modelleme yazılımları ile hazırlanmış 3 boyutlu modellerin kullanıldığı artırılmış gerçeklik (Küçük, Kapakin \& Göktaş, 2015), sanal gerçeklik (Lee \& Wong, 2014; Sun, Wu \& Cai, 2019) ve 3 boyutlu etkileşimli uygulamalar (Yılmaz, Karaman, Karakuş \& Göktaş, 2014) içeren çalışmalara ilginin artmakta olduğu görülmüştür.

3 boyutlu modelleme teknolojisinin kullanımının yaygınlaşması, 3 boyutlu modelleme eğitimlerinin de yaygınlaşmasına yol açmıştır. Özellikle, 1980'li yıllardan itibaren bilişim alanındaki gelişmelerle birlikte bilgisayar destekli tasarım ve modelleme ile ilgili dersler, mühendislik (Yue, 2008) ve mimarlık (Varinlioğlu, Alaçam, Başarır, Genca \& Üçok, 2016) ders müfredatlarına eklenmiştir. Bunun yanında, 3 boyutlu modelleme ile ilgili yazılımların kullanımı ve öğretimi STEM ve Maker hareketi gibi son yıllarda yaygınlaşmaya başlayan yenilikçi öğrenme ortamlarında da önemli yer tutmaya başlamıştır (Bull, Chiu, Berry, Lipson \& Xie, 2014; Taylor, 2016). Ülkemizde de konunun önemi fark edilmiş ve 3 boyutlu modelleme ile ilgili eğitim ve derslerin yükseköğretim kurumlarında verilmesi ile ilgili çalışmalar yapılmaya başlanmıştır. Bu çalışmalardan biri, Yükseköğretim Kurulunun (YÖK), 2018 yılında öğretmenlik programlarının ders müfredatları ile ilgili yaptığı 
güncelleme çalışmasıdır. Bu çalışma sonucu “Bilgisayar ve Öğretim Teknolojileri Öğretmenliği” programı müfredatına 3 boyutlu modelleme ile ilgili “Eğitimde Modelleme ve Tasarım” dersi eklenmiştir (YÖK, 2018). Bir diğer çalışma ise, YÖK'ün 2019 yılı üniversite tercih kılavuzunda yaptığı güncelleme çalışmasıdır (YÖK, 2019). Bu çalışmada, YÖK "3D modelleme ve animasyon" programını geleceğin mesleklerinden biri olarak göstermiş ve ilgili programa 2019 yılında ilk kez ön lisans düzeyinde öğrenci alımına olanak sağlamıştır.

Bilgisayar destekli 3 boyutlu modelleme teknolojisi öğrencilere özgün tasarımlar yapabilme fırsatı sunmaktadır. Öğrenciler tasarladıkları 3 boyutlu modelleri oyun motorları, artırılmış gerçeklik veya sanal gerçeklik gibi farklı dijital platformlarda kullanabileceği gibi, 3 boyutlu yazıcılar yardımıyla da somut ürünlere dönüştürebilirler. Dolayısıyla, 3 boyutlu modelleme teknolojilerinin kullanıldığı eğitim ortamları, öğrencilerin daha etkin ve üretken olmasına, John Dewey in ortaya attığı "yaparak yaşayarak öğrenme” modelinin gerçekleşmesine katkı sağlayabilir (Benzer \& Yıldız, 2019; Johnson, Adams Becker, Estrada \& Freeman, 2015; Maloy, Trust, Kommers, Malinowski \& LaRoche, 2017).

Bilgisayar destekli 3 boyutlu modelleme ve tasarım etkinliklerine yönelik öğrencilerin duygu ve düşüncelerini inceleyen araştırmalarda (Dere, 2017; Halıcı, Turhan, Aksu \& Varinlioğlu, 2017; Huang, Chen \& Lin, 2019; Martín-Dorta, Saorín \& Contero, 2008; Shavalier, 2004), öğrencilerin 3 boyutlu modelleme ve tasarım etkinliklerinden hoşlandıkları, etkinlikleri ilgi çekici olarak gördükleri ve etkinliklere yönelik olarak olumlu görüşler beyan ettikleri rapor edilmiştir.

Öğrenci tutumlarının incelenmesi, eğitim çalışmalarında sıklıkla ele alınan araştırma konularından biridir. Allport’a (1967; Akt. Tavşancıl, 2014) göre tutum; yaşantı ve deneyimler sonucu oluşan, ilgili olduğu nesne veya duruma karşı bireyin davranışlarını yönlendirmede etkili olan duygusal ve zihinsel durumdur. Katz’a (1960) göre ise, bireyin çevresindeki bir sembolü, bir nesneyi veya bir olayı olumlu veya olumsuz bir şekilde değerlendirme eğilimidir. Yapılan araştırmalar, öğrencilerin derse yönelik tutumları ile ders başarıları arasında pozitif yönde anlamlı bir ilişkinin bulunduğunu göstermiştir (Bakar vd., 2010; Birgin \& Demirkan, 2017; Nicolaidou \& Philippou, 2003; Peker \& Mirasyedioğlu, 2003; Yenilmez \& Özabacı, 2003; Yücel \& Koç, 2011). Öğrencilerin bir derse yönelik tutumlarının, o dersteki başarılarını belirleyen önemli faktörlerden biri olduğu alanyazında ifade edilmektedir (Ekici, 2002; Singh, Granville \& Dika, 2002; Ünal, Yılmaz \& Kardeş, 2019). Dolayısıyla, etkili ve verimli bir öğretimin gerçekleştirilmesi için ilgili derse/öğretime yönelik 
öğrenci tutumlarının incelenmesi önem arz etmektedir (Birgin \& Küçük, 2012; Yeşilyurt \& Gül, 2009). Öğrenci tutumlarını inceleyebilmek için ise geçerlik ve güvenirlik çalışması yapılmış ölçme araçlarına ihtiyaç vardır. 3 boyutlu modelleme ve tasarım ile ilgili alanyazının incelenmesi sonucu, öğrencilerin 3 boyutlu modellemeye yönelik tutumlarını ölçebilecek geçerlik ve güvenirlik çalışması yapılmış herhangi bir ölçme aracına rastlanmamıştır. Gerçekleştirilen çalışma ile alanyazındaki bu boşluğun giderilmesi amaçlanmıştır. Konu üzerine yapılan inceleme sonucu, araştırmaların çoğunun 3 boyutlu modelleme ve tasarım etkinliklerinin öğrencilerin uzamsal yetenek gibi bilişsel özellikleri üzerine etkisini incelemeye odaklanmış oldukları (Kurtuluş \& Uygan, 2010; Martín-Dorta, Saorín \& Contero, 2008; Šafhalter, Vukman \& Glodež, 2016; Toptaş, Çelik \& Karaca, 2012), tutum gibi duyuşsal özellikler üzerine ise sadece birkaç çalışma olduğu görülmüştür. Çalışmanın amacı, üniversite öğrencilerinin 3 boyutlu modellemeye ve dersine yönelik tutumlarını inceleyebilecek geçerli ve güvenilir bir ölçme aracı geliştirmektir. Çalışmanın hem ulusal hem de uluslararası alanyazına katkı sağlayacağı düşünülmektedir.

\section{Yöntem}

\section{Araştırma Deseni}

Araştırma, tarama modelinde yürütülmüştür. Tarama araştırmalarında amaç, var olan bir durumu olduğu gibi betimlemektir (Karasar, 2016).

\section{Katılimcilar}

Çalışmanın örneklemini, öğrenim gördüğü programda 3 boyutlu modelleme ile ilgili ders almış ve gönüllü 204 üniversite öğrencisi oluşturmuştur. Katılımcıların \% 57`si erkek \% 43 ü kadın öğrencidir.

\section{Veri Toplama Aracı}

Çalışmada, katılımcıların 3 boyutlu modellemeye ve dersine yönelik tutumlarını incelemek amacıyla araştırmacılar tarafından tutum ölçeği geliştirilmiştir. 3 boyutlu modelleme ve dersine yönelik tutum ölçeği geliştirme aşamaları:

- Taslak maddelerin oluşturulması: Tutum ölçeği geliştirme çalışmaları incelenmiş ve 42 maddelik taslak madde havuzu oluşturulmuştur.

- Uzman görüşlerinin alınması: Eğitim alanında doktorasını tamamlamış ve 3 boyutlu modelleme hakkında bilgi sahibi iki akademisyenin görüşleri doğrultusunda taslak madde havuzundan dört madde çıkarılmıştır. 
- $\quad$ Pilot çalışmanın yapılması: Taslak ölçekle ilgili maddelerin anlaşılırlı̆̆g ve cevaplama süresinin belirlenmesi için sekiz öğrenciyle pilot çalışma gerçekleştirilmiştir.

- Asıl çalışmanın yapılması: Geliştirilen taslak ölçeğin geçerlik ve güvenirlik çalışması için öğrenim gördügü programda 3 boyutlu modelleme ile ilgili ders almış, gönüllü 204 üniversite öğrencisine ölçek uygulanmış ve veriler toplanmıştır.

\section{Veri Analizi}

Ölçek 5 'li likert tipinde hazırlanmıştır. Düzeyleri belirlemek için sırasıyla “Tamamen Katıliyorum”, “Katılıyorum”, “Kararsızım”, “Katılmıyorum” ve “Kesinlikle Katılmıyorum” seçenekleri kullanılmıştır. Olumlu maddeler 5 `en 1`e, olumsuz maddeler 1 `den 5 `e doğru sayısal değerler verilerek puanlanmıştır. Ölçek verilerinin analizi için SPSS yazılımı kullanılmıştır. Ölçeğin geçerlik ve güvenirliği için toplanan veriler üzerinde temel bileşen analizi yöntemi ile varimax döndürme tekniği kullanılarak açımlayıcı faktör analizi (AFA) yapılmıştır. Ölçme aracının güvenirlik katsayısı hesaplanmıştır. Güvenilirlik katsayısı olarak Cronbach Alpha $(\alpha)$ değeri kullanılmıştır. Ayrıca elde edilen yapıya ilişkin doğrulayıcı faktör analizi (DFA) gerçekleştirilmiştir.

\section{Bulgular}

AFA gerçekleştirmeden önce verilerin faktör analizine uygunluğu incelenmiştir. Yapılan analizin sonucu Tablo 1`de gösterilmiştir. Tablo 1`e göre KMO testi katsayısı 0,917 olarak hesaplanmış ve Bartlett Küresellik testi anlamlı olarak bulunmuştur. KMO değerinin 0,60'dan yüksek ve Bartlett testinin anlamlı çıkması, verilerin faktör analizine uygun olduğu anlamina gelmektedir (Büyüköztürk, 2017).

Tablo 1. Ölçek ile ilgili KMO-Bartlett testi sonucu

\begin{tabular}{lll}
\hline KMO Test Katsayıs1 & & 0,917 \\
\hline Bartlett Test Katsayısı & Ki-Kare & 4656,392 \\
\cline { 2 - 3 } & Serbestlik Derecesi & 703 \\
\cline { 2 - 3 } & Anlamlllk &, 000 \\
\hline
\end{tabular}

Faktör sayısının belirlenmesinde öz değerleri 1'den büyük olan faktörler dikkate alınmalıdır (Büyüköztürk, 2017). Çalışmada öz değeri 1'den büyük, toplam varyansın \% 66'sını açıklayan 8 alt faktör ortaya çıkmıştır. Çalışma için öz değerin 2 olmasına karar verilmiştir. Bu durumda faktör sayısı 3, açıklanan varyans ise \% 50 olarak hesaplanmıştır. Şekil 1`de verilen yamaç-birikinti grafiği incelendiğinde de ölçeğin üç faktörden meydana geldiği görülmektedir. 


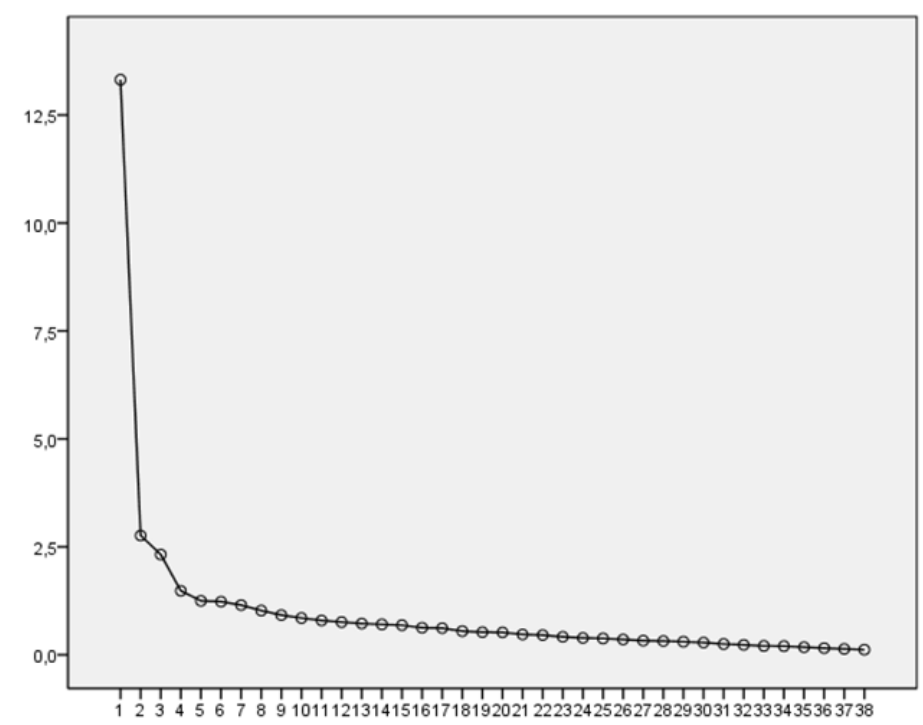

Şekil 1. Yamaç-birikinti grafiği

AFA sürecinde madde eleme için aşağıdaki ölçütler dikkate alınmıştır:

- Faktör analizi için en düşük faktör yük değeri 0,45 (eşik değer) olarak kabul edilmiş olup bu değerin altındaki maddeler elenmiştir. Maddelerin bulundukları faktörde yüksek yük değerine sahip olmaları istenir. Faktör yük değeri olarak 0,45 ve üzerinin seçilmesi iyi bir ölçüdür (Büyüköztürk, 2017).

- Birden fazla faktöre anlamlı yük veren maddelerin (binişik madde) en yüksek iki değeri arasındaki fark 0,10`dan az ise bu maddeler elenmiştir (Büyüköztürk, 2017).

- Madde-toplam korelasyon değeri 0,30'un altında olan maddelerin elenmesine karar verilmiştir (Büyüköztürk, 2017).

AFA esnasında maddeler ölçekten tek tek çıkarılmış ve her defasında analiz tekrar edilmiştir. Madde atılması işlemine öncelikle en düşük farka sahip binişik maddeden başlanılmıştır. Binişik maddenin kalmaması durumunda eşik değerin altında ve en düşük faktör yük değerine sahip madde elenmiştir (Çokluk, Şekercioğlu \& Büyüköztürk, 2016). AFA sürecinde elenecek madde bulunmaması durumunda ölçek maddeleri için maddetoplam korelasyon tablosu incelenmiş 0,30 un altında değere sahip madde olup olmadığ araştırılmıştır. Madde-toplam korelasyon tablosunda 0,30`un altında her hangi bir maddeye rastlanmamıştır. AFA sonucunda, otuz maddeden oluşan toplam varyansın \% 54'ünü açıklayan ve üç faktörden oluşan bir ölçek elde edilmiştir. Elde edilen faktörlere, maddelerin içerikleri ile uyumlu olacak şekilde birinci faktöre "Önem", ikinci faktöre "İlgi", üçüncü faktöre ise "Kayg1" isimleri verilmiştir. Ölçekte bulunan olumlu madde sayısı 16, olumsuz madde sayısı 14 tür. Ölçek maddelerinin alt faktörlere göre dağılımları ve faktör yük 
değerleri Tablo 2 'de verilmiştir. Tablo 2 ye göre maddelere ait faktör yük değerleri 0,46 0,80 arasında değişmektedir.

Elde edilen ölçeğin madde analizi için ölçek toplam puanına göre \% 27`lik alt grup ve üst grup arasında bağımsız gruplar t-testi gerçekleştirilmiştir. Gerçekleştirilen t-testi sonuçları Tablo 2 'de verilmiştir. Analiz sonucuna göre tüm maddeler için üst \% 27'lik gruba ait madde puan ortalamalarının alt \% 27'lik gruba ait madde puan ortalamalarından anlamlı $(\mathrm{p}<, 001)$ olarak daha yüksek olduğu belirlenmiştir. Tablo 2 ye göre t-testi değerleri 4,41 12,66 arasında değişmektedir. Bu sonuca göre ölçekte yer alan maddeler farklı tutuma sahip katılımcıları anlamlı şekilde ayırt edebilmektedir.

Tablo 2. Ölçek maddelerine ilişkin analiz sonuçları

\begin{tabular}{|c|c|c|c|c|c|c|}
\hline \multirow[b]{2}{*}{ Madde No } & \multicolumn{3}{|c|}{ Faktörler } & \multirow{2}{*}{$\begin{array}{c}\text { Faktör Ortak } \\
\text { Varyansı }\end{array}$} & \multirow{2}{*}{$\begin{array}{c}\text { Madde-Toplam } \\
\text { Korelasyonu }\end{array}$} & \multirow[b]{2}{*}{ t (Alt $\% 27-U ̈ s t \% 27)$} \\
\hline & Önem & İlgi & Kayg1 & & & \\
\hline M19 & 0,804 & & & 0,735 & 0,700 & 9,908 \\
\hline$\overline{\mathrm{M} 18}$ & 0,744 & & & 0,601 & 0,618 & 10,129 \\
\hline M10 & 0,743 & & & 0,637 & 0,663 & 10,009 \\
\hline M20 & 0,688 & & & 0,556 & 0,627 & 9,577 \\
\hline$\overline{\mathrm{M} 8}$ & 0,686 & & & 0,521 & 0,575 & 7,185 \\
\hline M14 & 0,619 & & & 0,503 & 0,633 & 11,026 \\
\hline M15 & 0,616 & & & 0,485 & 0,611 & 9,163 \\
\hline M22 & 0,611 & & & 0,570 & 0,697 & 11,311 \\
\hline M36 & 0,579 & & & 0,345 & 0,379 & 4,412 \\
\hline M27 & 0,526 & & & 0,443 & 0,566 & 7,287 \\
\hline M32 & 0,489 & & & 0,397 & 0,572 & 8,523 \\
\hline M34 & & 0,735 & & 0,562 & 0,534 & 9,056 \\
\hline M33 & & 0,719 & & 0,618 & 0,625 & 11,418 \\
\hline M5 & & 0,706 & & 0,613 & 0,659 & 10,965 \\
\hline M28 & & 0,651 & & 0,669 & 0,654 & 11,730 \\
\hline M25 & & 0,642 & & 0,658 & 0,718 & 12,520 \\
\hline$\overline{\mathrm{M} 6}$ & & 0,642 & & 0,659 & 0,747 & 12,655 \\
\hline M11 & & 0,621 & & 0,474 & 0,499 & 8,733 \\
\hline M9 & & 0,621 & & 0,405 & 0,440 & 7,628 \\
\hline M1 & & 0,577 & & 0,455 & 0,523 & 7,482 \\
\hline M12 & & 0,549 & & 0,531 & 0,610 & 10,096 \\
\hline M23 & & 0,478 & & 0,433 & 0,611 & 8,979 \\
\hline M7 & & 0,476 & & 0,520 & 0,681 & 10,755 \\
\hline M26 & & 0,466 & & 0,405 & 0,532 & 6,445 \\
\hline M17 & & 0,456 & & 0,392 & 0,522 & 7,993 \\
\hline M30 & & & 0,784 & 0,690 & 0,539 & 8,209 \\
\hline M24 & & & 0,778 & 0,641 & 0,459 & 7,185 \\
\hline M29 & & & 0,767 & 0,654 & 0,517 & 8,145 \\
\hline M4 & & & 0,672 & 0,494 & 0,372 & 5,802 \\
\hline M37 & & & 0,553 & 0,467 & 0,410 & 5,713 \\
\hline
\end{tabular}

Ölçeğe ilişkin AFA gerçekleştirildikten sonra ölçeğin tamamı ve her bir faktör için ayrı ayrı güvenirlik katsayısı bulunmuştur. Sonuçlar Tablo 3 'te verilmiştir. 30 maddelik ölçeğin tamamının güvenirlik katsayısı 0,94 tür. Birinci faktöre için güvenirlik katsayısı 0,90, ikinci faktöre için güvenirlik katsayısı 0,91, üçüncü faktöre için güvenirlik katsayısı ise 0,82 
olarak tespit edilmiştir. Güvenilirlik katsayısının 0,70 veya daha yüksek olması test puanlarının güvenirliği için yeterli görülmektedir (Büyüköztürk, 2017).

Tablo 3. Faktörler ve güvenirlik katsayıları

\begin{tabular}{lcc}
\hline Faktör Adı & Madde Sayısı & Güvenirlik Katsayısı \\
\hline Önem & 11 & 0,90 \\
\hline İgi & 14 & 0,91 \\
\hline Kaygı & 5 & 0,82 \\
\hline Ölçeğin Tamamı & 30 & 0,94 \\
\hline
\end{tabular}

AFA sonucu çıkan modelin değerlendirilmesi için AMOS yazılımı aracılığıyla DFA yapılmıştır. Kline (2005) DFA çalışmalarında en azından Ki-Kare, SRMR, RMSEA ve CFI uyum indekslerinin rapor edilmesini önermektedir. Bu araştırmada, model uyumu için KiKare $(\chi 2) / d f$, SRMR, GFI, AGFI, RMSEA ve CFI uyum indeksleri dikkate alınmıştır. DFA'ya ilişkin path diyagramı Şekil 2 'de gösterilmiştir.

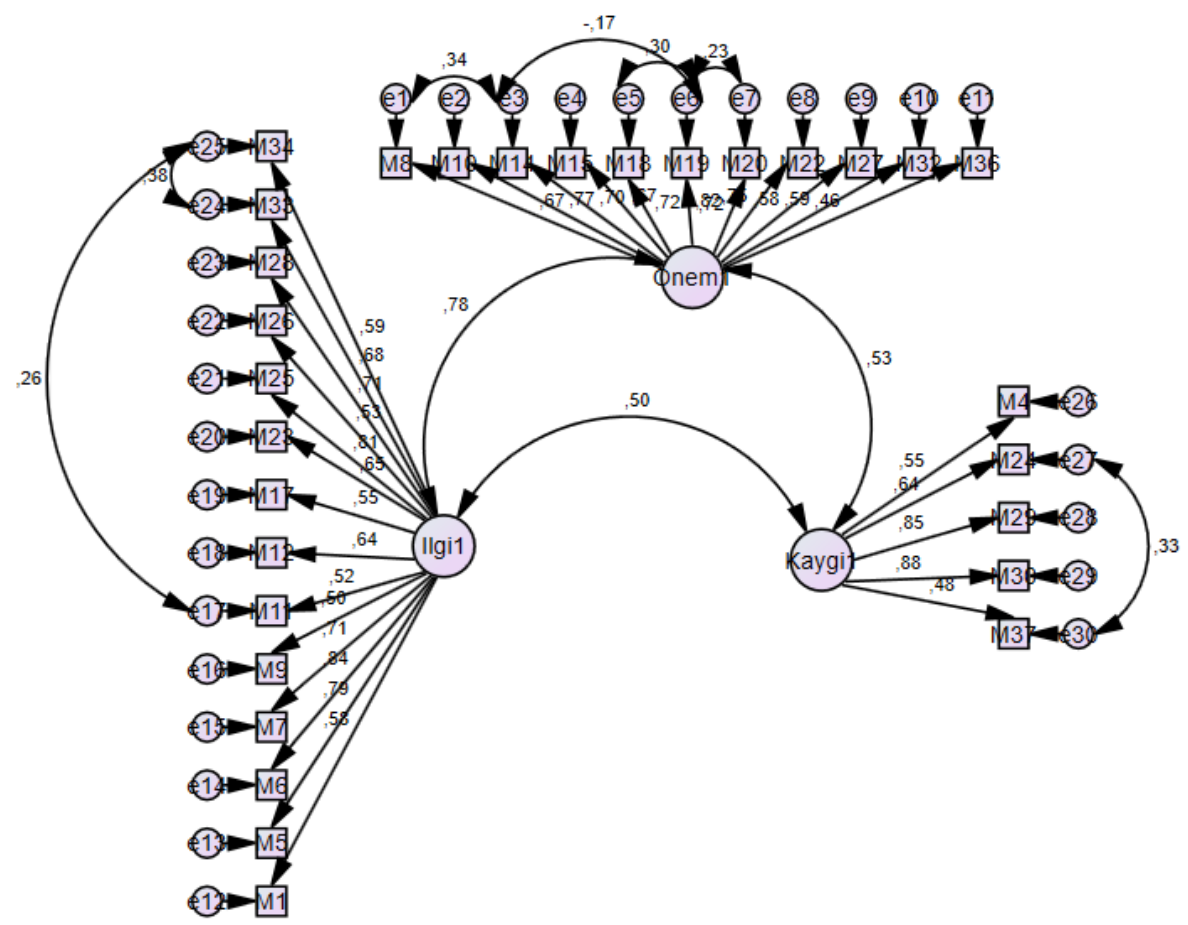

Şekil 2. Doğrulayıcı faktör analizi sonuçları

AFA sonucu elde edilen yapının DFA sürecinde mevcut model üzerinde önerilen modifikasyon işlemleri gerçekleştirilmeden önce elde edilen uyum indeks değerleri şöyledir: $[\chi 2 / \mathrm{df}=2,693, \mathrm{SRMR}=0,074, \mathrm{GFI}=0,75, \mathrm{AGFI}=0,71, \mathrm{RMSEA}=0,091$ ve $\mathrm{CFI}=0,80] . \mathrm{DFA}$ sonucunda önerilen modifikasyonlar dikkate alınarak gerçekleştirilen analiz sonucu uyum indeks değerleri şu şekilde oluşmuştur: $[\chi 2 / \mathrm{df}=2,406, \mathrm{SRMR}=0,071, \mathrm{GFI}=0,77, \mathrm{AGFI}=0,73$, $\operatorname{RMSEA}=0,08$ ve CFI $=0,84]$. Uyum indeksleri incelendiğinde $\chi 2 / \mathrm{df}$ uyum değerinin 2,406 olduğu görülmektedir. Kline`a (2005; Akt. Çokluk vd., 2016) göre küçük örneklemler için bu 
değerin 2,5 ve altında olması modelin mükemmel uyuma sahip olduğunu göstermektedir. Dolayısıyla bu çalışmadaki $\chi 2 / d f$ değeri mükemmel uyumu göstermektedir. SRMR indeks değeri 0,071 olarak hesaplanmıştır. Schermelleh-Engel, Moosbrugger \& Müller`e (2003) göre bu değer modelin kabul edilebilir uyuma sahip olduğunu göstermektedir. GFI değeri 0,77 ve AGFI değeri 0,73 olarak hesaplanmıştır. Bu değerlerin 0,90 ve daha büyük olması modelin iyi uyum gösterdiğine işaret etmektedir (Schumacker \& Lomax, 2010). Ancak GFI ve AGFI indeks değerleri örneklem büyüklüğünden oldukça fazla etkilenmektedir (Anderson \& Gerbing, 1984). GFI ve AGFI uyum indeksleri DFA çalışmalarında sıklıkla raporlanmasına rağmen sahip oldukları güven sorunları ve zayıf performanslarından dolayı kullanılmaları önerilmemektedir (Hooper, Coughlan \& Mullen, 2008; Koyuncu \& K1lı̧, 2019). RMSEA değeri 0,08 olarak hesaplanmıştır. Schermelleh-Engel, Moosbrugger \& Müller`e (2003) göre bu değer modelin kabul edilebilir uyuma sahip olduğunu göstermektedir. CFI değeri 0,84 olarak hesaplanmıştır. Sümer`e (2000; Akt. Çokluk vd., 2016) göre bu değerin 0,90 ve daha büyük olması modelin iyi uyum gösterdiğini belirtir. Çalışmadaki CFI indeksinin 0,90 değerine oldukça yakın olması, modelin nispeten iyi uyum gösterdiğine işaret etmektedir.

\section{Tartışma, Sonuç ve Öneriler}

Bilgisayar destekli 3 boyutlu modelleme teknolojilerinin kullanımı ve öğretimi, eğitim ortamlarında hızla yaygınlaşmaktadır. Yaygınlaşan bu yenilikçi teknolojiye yönelik öğrenci tutumlarının incelenmesi önem arz etmektedir. Çalışmada, üniversite öğrencilerinin 3 boyutlu modellemeye ve dersine yönelik tutumlarını ölçebilecek geçerli ve güvenilir bir ölçme aracı geliştirmek amaçlanmıştır. Bu amaç için elde edilen veriler üzerinde AFA ve DFA işlemleri yürütülmüştür. Yapılan analizler sonucunda, otuz maddeden oluşan toplam varyansın \% 54'ünü açıklayan, üç faktörlü bir ölçek geliştirilmiştir. Ölçeği oluşturan faktörlere, içerdikleri maddelerin içerikleri ile uyumlu olacak şekilde birinci faktöre "Önem", ikinci faktöre "İlgi”, üçüncü faktöre ise "Kayg1" isimleri verilmiştir. Ölçekte bulunan olumlu madde sayısı 16, olumsuz madde sayısı 14 tür. Açıklanan varyansın tek faktörlü desenlerde \% 30 ve daha fazla olması yeterli görülebilirken çok faktörlü desenlerde ise bu değerin daha yüksek olması beklenir (Büyüköztürk, 2017). Scherer, Wiebe, Luther ve Adams`e (1988; Akt. Tavşancıl, 2014) göre sosyal bilimlerde çok faktörlü ölçek yapılarında, açıklanan varyansın \% 40 ile \% 60 arasında olması yeterli kabul edilir. İlgili referans değerlerine göre açıklanan varyans değerinin yeterli olduğu söylenebilir. 
Ölçek maddelerine ait faktör yük değerleri 0,46 - 0,80 arasında değişmektedir. Faktör yük değerlerinin 0,45 ve üzeri olması uygun görülmektedir (Büyüköztürk, 2017). İlgili referans değerine göre faktör yük değerlerinin yeterli düzeyde olduğu söylenebilir.

Madde analizi için \% 27`lik alt ve üst grup toplam puanları arasında gerçekleştirilen bağımsız gruplar t-testi sonuçlarına göre ölçekte yer alan tüm maddeler farklı tutuma sahip katılımcıları anlamlı şekilde ayırt edebilmektedir. Toplam otuz maddeden oluşan ölçeğin tamamı için güvenirlik katsayısı 0,94, alt faktörlere ait güvenirlik katsayıları ise sırasıyla 0,90, 0,91 ve 0,82 olarak hesaplanmıştır. Güvenilirlik katsayısının 0,70 veya daha yüksek olması yeterli olarak kabul edilmektedir (Büyüköztürk, 2017). İlgili referans değerine göre güvenirlik katsayı değerlerinin yeterli düzeyde olduğu söylenebilir. DFA sonucu elde edilen uyum indeksleri, AFA ile elde edilen üç faktörlü yapının uygunluğuna işaret etmektedir. Analizlerden elde edilen değerler, alanyazındaki referans değerlere göre değerlendirildiğinde ortaya çıkan ölçeğin geçerli ve güvenilir bir ölçme aracı olduğu söylenebilir.

Bilgisayar destekli 3 boyutlu modelleme üzerine eğitimler, üniversitelerin lisans / ön lisans düzeyindeki bilişim ve tasarım ile ilgili programlarda, ortaokul ve lise öğrencilerine yönelik düzenlenen STEM ve STEAM etkinliklerinde görülmeye başlanmıştır. Geliştirilmiş ölçek yardımıyla, öğrencilerin 3 boyutlu modellemeye yönelik tutumları cinsiyet, sınıf düzeyi, bölüm/program gibi çeşitli değişkenler açısından incelenebilir. Bununla birlikte, 3 boyutlu modelleme öğretimi üzerine gerçekleştirilecek deneysel çalışmalarda süreç içerisinde öğrencilerin tutumlarındaki değişim analiz edilebilir.

\section{Bilgilendirme}

Bu çalışma, birinci yazarın doktora tezinden üretilmiş olup 19-22 Haziran 2019 tarihleri arasinda Ankara Üniversitesi nde düzenlenen VIth International Eurasian Educational Research Congress (EJER 2019) Kongresi`nde sözlü bildiri olarak sunulmuştur.

Bu çalışmada kullanılan veriler 2020 yılı öncesine ait olduğu araştırmacılar tarafından onaylanmıştır.

Yazar Katkı Beyanı

Ali İhsan BENZER: Kavramsallaştırma, Metodoloji, Ölçme Aracı Geliştirme, Veri Toplama ve Analizi, Ön Taslak Yazımı ve Düzenleme

Bünyamin YILDIZ: Kavramsallaştırma, Metodoloji, Danışmanlık ve Denetim, İncelemeYazma ve Düzenleme 


\section{Kaynaklar}

Anderson, J. C., \& Gerbing, D. W. (1984). The effect of sampling error on convergence, improper solutions, and goodness-of-fit indices for maximum likelihood confirmatory factor analysis. Psychometrika, 49(2), 155-173.

Bakar, K. A., Tarmizi, R. A., Mahyuddin, R., Elias, H., Luan, W. S., \& Ayub, A. F. M. (2010). Relationships between university students' achievement motivation, attitude and academic performance in Malaysia. Procedia-Social and Behavioral Sciences, 2(2), 4906-4910.

Benzer, A. I., \& Yıldız, B. (2019). The effect of computer-aided 3D modeling activities on preservice teachers' spatial abilities and attitudes towards 3D modeling. Journal of Baltic Science Education, 18(3), 335-348.

Birgin, O., \& Demirkan, H. (2017). Yatılı bölge ortaokulu öğrencilerinin matematiğe yönelik tutumlarının bazı değişkenler bakımından incelenmesi. E-Uluslararası Eğitim Araştırmaları Dergisi, 8(2), 1-15.

Birgin, O., \& Küçük, M. (2012). Alternatif ölçme-değerlendirme araç ve yöntemleri. M. Küçük \& Y. Geçit (Eds.), Eğitimde Ölçme ve Değerlendirme (s. 159-220). Ankara: Nobel Akademik Yayıncılık.

Bull, G., Chiu, J., Berry, R., Lipson, H., \& Xie, C. (2014). Advancing children's engineering through desktop manufacturing. J.M. Spector, M.D. Merrill, J. Elen, \& M.J. Bishop (Eds.) Handbook of research on educational communications and technology (s. 675-688). New York: Springer.

Büyüköztürk, Ş. (2017). Sosyal bilimler için veri analizi el kitabı. Ankara: Pegem Akademi.

Çokluk, Ö., Şekercioğlu, G. ve Büyüköztürk, Ş. (2016). Sosyal bilimler için çok değişkenli istatistik SPSS ve LISREL uygulamaları. Ankara: Pegem Akademi.

Dere, H. E. (2017). Web tabanl 3B tasarım uygulamalarının ortaokul öğrencilerinin uzamsal görselleştirme ve zihinsel döndürme becerilerine etkisi. (Yayımlanmamış Yüksek Lisans Tezi). Başkent Üniversitesi, Eğitim Bilimleri Enstitüsü, Ankara.

Ekici, G. (2002). Biyoloji öğretmenlerinin laboratuvar dersine yönelik tutum ölçeği (BÖLDYTÖ). Hacettepe Üniversitesi Ĕ̆itim Fakültesi Dergisi, 22, 62-66.

Halıcl, S. M., Turhan, G. D., Aksu, M. S., \& Varinlioğlu, G. (2017, Haziran). Uzay mimarlığında sayısal tasarım ve üretim araçlarının değerlendirilmesi üzerine Mars özelinde bir çalışma. A. Gönenç Sorguç, Ç. F. Özgenel \& M. Kruşa Yemişcioğlu (Ed.), 11. Mimarlıkta Sayısal Tasarım Ulusal Sempozyumu Bildiri Kitabı (s. 22-31) içinde, Ankara.

Hooper, D., Coughlan, J., \& Mullen, M. R. (2008). Structural equation modelling: Guidelines for determining model fit. Electronic Journal of Business Research Methods, 6(1), 53-60.

Huang, T. C., Chen, M. Y., \& Lin, C. Y. (2019). Exploring the behavioral patterns transformation of learners in different 3D modeling teaching strategies. Computers in Human Behavior, 92, 670-678.

Johnson, L., Adams Becker, S., Estrada, V., \& Freeman, A. (2015). NMC horizon report: 2015 K12 edition. Austin, Texas: The New Media Consortium.

Karasar, N. (2016). Bilimsel araştırma yöntemi: Kavramlar, ilkeler, teknikler (31. Basım), Ankara: Nobel Akademik Yayıncilık.

Katz, D. (1960). The functional approach to the study of attitudes. Public Opinion Quarterly, 24(2), 163-204.

Kline, R. B. (2005). Principles and practice of structural equation modeling (2. Basım), New York: Guilford Press.

Koyuncu, İ., \& Kılıç, A. F. (2019). Açımlayıcı ve doğrulayıcı faktör analizlerinin kullanımı: Bir doküman incelemesi. Eğitim ve Bilim, 44(198), 361-388. 
Kurtuluş, A., \& Uygan, C. (2010). The effects of Google Sketchup based geometry activities and projects on spatial visualization ability of student mathematics teachers. Procedia Social and Behavioral Sciences, 9, 384-389.

Küçük, S., Kapakin, S., \& Göktaş, Y. (2015). Tıp fakültesi öğrencilerinin mobil artırılmış gerçeklikle anatomi öğrenimine yönelik görüşleri. Yükseköğretim ve Bilim Dergisi, 5(3), 316-323.

Lee, E. A. L., \& Wong, K. W. (2014). Learning with desktop virtual reality: Low spatial ability learners are more positively affected. Computers $\mathcal{E}$ Education, 79, 49-58.

Maloy, R., Trust, T., Kommers, S., Malinowski, A., \& LaRoche, I. (2017). 3D modeling and printing in history/social studies classrooms: Initial lessons and insights. Contemporary Issues in Technology and Teacher Education, 17(2), 229-249.

Martín-Dorta, N., Saorín, J. L., \& Contero, M. (2008). Development of a fast remedial course to improve the spatial abilities of engineering students. Journal of Engineering Education, 97(4), 505-513.

Nicolaidou, M., \& Philippou, G. (2003). Attitudes towards mathematics, self-efficacy and achievement in problem solving. European Research in Mathematics Education III. Thematic Group 2, 1-11.

O'Malley, S., 2015. 3D modeling and animation. http://um3d.dc.umich.edu/wpcontent/uploads/2015/10/3D-Modeling-and-Animation-Novice.pdf adresinden erişildi

Peker, M., \& Mirasyedioğlu, Ş. (2003). Lise 2. sınıf öğrencilerinin matematik dersine yönelik tutumları ve başarıları arasındaki ilişki. Pamukkale Üniversitesi Ĕ̆itim Fakültesi Dergisi, $14,157-166$.

Šafhalter, A., Vukman, K. B., \& Glodež, S. (2016). The effect of 3D-modeling training on students' spatial reasoning relative to gender and grade. Journal of Educational Computing Research, 54(3), 395-406.

Schermelleh-Engel, K., Moosbrugger, H., \& Müller, H. (2003). Evaluating the fit of structural equation models: Tests of significance and descriptive goodness-of-fit measures. Methods of Psychological Research Online, 8(2), 23-74.

Schumacker, R. E., \& Lomax, R. G. (2010). A beginner's guide to structural equation modeling (3. Basım). New York: Routledge / Taylor \& Francis.

Shavalier, M. (2004). The effects of CAD-like software on the spatial ability of middle school students. Journal of Educational Computing Research, 31(1), 37-49.

Singh, K., Granville, M., \& Dika, S. (2002). Mathematics and science achievement: Effects of motivation, interest, and academic engagement. The Journal of Educational Research, 95(6), 323-332.

Spallone, R. (2015). Digital reconstruction of demolished architectural masterpieces, 3D modeling, and animation: The Case Study of Turin Horse Racing by Mollino. S. Brusaporci (Ed.), Handbook of research on emerging digital tools for architectural surveying, modeling, and representation (s. 476-509). Hershey: IGI Global.

Sun, R., Wu, Y. J., \& Cai, Q. (2019). The effect of a virtual reality learning environment on learners' spatial ability. Virtual Reality, 23(4), 385-398.

Tavşancıl, E. (2014). Tutumların ölçülmesi ve SPSS ile veri analizi (5. Basım), Ankara: Nobel Akademik Yayıncılık.

Taylor, B. (2016). Evaluating the benefit of the maker movement in K-12 STEM education. Electronic International Journal of Education, Arts, and Science (EIJEAS), 2, 1-22.

Toptaş, V., Çelik, S., \& Karaca, E. T. (2012). Improving 8th grades spatial thinking abilities through a 3D modeling program. The Turkish Online Journal of Educational Technology (TOJET), 11(2), 128-134. 
Varinlioğlu, G., Alaçam, S., Başarır, L., Genca, Ö., \& Üçok, I. (2016). Bilgisayar destekli teknik çizimde yeni yaklaşımlar: Temsil araçları arası dönüşüm. Yapı, 419, Ekim, 137-141.

Ünal, S., Yılmaz, S. N., Kardeş, E. (2019, Nisan). Karikatür destekli bilim tarihi temelli hikâyeleri içeren öğretim sürecine yönelik öğrenci görüşleri: Joule-Thomson olayı. M. Riedler, M. Küçük, S. Z. Genç \& M. Y. Eryaman (Ed.), XII. Uluslararası Ĕ̆itim Araştırmaları Kongresi Bildiriler Kitabı Kongre Tam Metin Kitabı (s. 846-856) içinde, Eğitim Araştırmaları Birliği, Rize.

Yenilmez, K., \& Özabacı, N. Ş. (2003). Yatılı öğretmen okulu öğrencilerinin matematik ile ilgili tutumları ve matematik kaygı düzeyleri arasındaki ilişki üzerine bir araştırma. Pamukkale Üniversitesi Ĕ̆itim Fakültesi Dergisi, 14, 132-146.

Yeşilyurt, S., \& Gül, Ş. (2009). Biyoloji tutum ölçeği. Erzincan Üniversitesi Eğitim Fakültesi Dergisi, 11(2), 239-258.

Yılmaz, R. M., Karaman, A., Karakuş, T., \& Göktaş, Y. (2014). İlköğretim öğrencilerinin 3 boyutlu sanal öğrenme ortamlarına yönelik tutumları: Second Life örneği. Ege Eğitim Dergisi, 15(2), 538-555.

Yue, J. (2008). Spatial visualization by realistic 3D views. Engineering Design Graphics Journal, 72(1), 28-38.

Yücel, Z., \& Koç, M. (2011). İlköğretim öğrencilerinin matematik dersine karşı tutumlarının başarı düzeylerini yordama gücü ile cinsiyet arasındaki ilişki. İlköğretim Online, 10(1), 133-143.

Yükseköğretim Kurulu [YÖK]. (2018). Bilgisayar ve öğretim teknolojileri öğretmenliği lisans programi.

YÖK, http://www.yok.gov.tr/documents/10279/41805112/Bilgisayar_ve_Ogretim_Teknolojile ri_Ogretmenligi_Lisans_Programi.pdf adresinden erişildi.

Yükseköğretim Kurulu [YÖK]. (2019). 2019 Yükseköğretim kontenjanlarına ilişkin açıklama. YÖK, https:// Www.yok.gov.tr/HaberBelgeleri/Haber/2019/58-2019-YKSKontenjanlari/2019_yks_kontenjanlarina_iliskin_aciklama.pdf adresinden erişildi. 
EK 1.3 boyutlu modelleme ve dersine yönelik tutum ölçeği

\begin{tabular}{|c|c|c|c|c|c|}
\hline 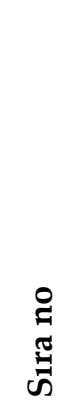 & 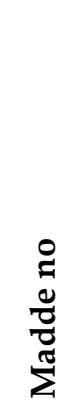 & Maddeler & E & 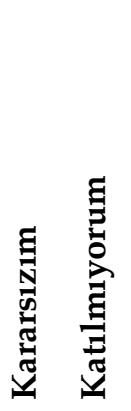 & 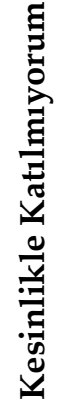 \\
\hline 1 & M1 & 3 boyutlu modelleme ile ilgili yeniliklerden haberdar olmak isterim. & & & \\
\hline 2 & M4 & 3 boyutlu modelleme dersindeki konuları anlamakta zorlanıyorum. & & & \\
\hline 3 & M5 & 3 boyutlu modelleme programları kullanmaktan hoşlanırım. & & & \\
\hline 4 & M6 & 3 boyutlu modelleme ile ilgili çalışmalar yapmaktan zevk alırım. & & & \\
\hline 5 & M7 & 3 boyutlu modelleme dersi sevdiğim bir derstir. & & & \\
\hline 6 & M8 & 3 boyutlu modelleme ile uğraşmak boşa zaman kaybıdır. & & & \\
\hline 7 & M9 & 3 boyutlu modelleme dersi benim için diğer derslerden daha önemlidir. & & & \\
\hline 8 & M10 & 3 boyutlu modelleme dersi olduğunda bilg. laboratuvarına girmek istemem. & & & \\
\hline 9 & M11 & 3 boyutlu modelleme ile ilgili güncel gelişmeleri takip ederim. & & & \\
\hline 10 & M12 & 3 boyutlu modelleme dersinde kendimi diğer derslerden daha rahat hissederim. & & & \\
\hline$\overline{11}$ & M14 & 3 boyutlu modelleme ile uğraşmak bana anlamsız geliyor. & & & \\
\hline 12 & M15 & 3 boyutlu modelleme öğrenmenin bana mesleki anlamda hiçbir katkısı yoktur. & & & \\
\hline 13 & M17 & $\begin{array}{l}3 \text { boyutlu modelleme bilgimin ileriki yaşamımda bana bir ayrıcalık getireceğini } \\
\text { düşünüyorum. }\end{array}$ & & & \\
\hline 14 & M18 & Seçmeli ders alacaklara 3 boyutlu modelleme dersini tavsiye etmem. & & & \\
\hline 15 & M19 & 3 boyutlu modelleme dersi sıkıcı bir derstir. & & & \\
\hline 16 & M20 & Zorunda olmazsam 3 boyutlu modelleme dersine girmezdim. & & & \\
\hline 17 & M22 & 3 boyutlu modelleme dersine sadece dersi geçmek için çalışırım. & & & \\
\hline 18 & M23 & 3 boyutlu modelleme dersi bilişsel ve zihinsel anlamda bana katkıda bulunur. & & & \\
\hline 19 & M24 & 3 boyutlu modelleme programlarını öğrenmek zordur. & & & \\
\hline 20 & M25 & 3 boyutlu modelleme ile ilgili daha fazla şey öğrenmek isterim. & & & \\
\hline 21 & M26 & $\begin{array}{l}\text { Gelecekte } 3 \text { boyutlu modelleme programlarının kullanımının yaygınlaşacağını } \\
\text { düşünüyorum. }\end{array}$ & & & \\
\hline 22 & M27 & Gelecekte 3 boyutlu modellemenin öneminin artacağını düşünüyorum. & & & \\
\hline 23 & M28 & 3 boyutlu modelleme programlarını kolayca kullanabilirim. & & & \\
\hline 24 & M29 & 3 boyutlu modelleme dersi sınavını düşünmek beni kaygılandırır. & & & \\
\hline 25 & M30 & 3 boyutlu modelleme dersi sınavları beni korkutur. & & & \\
\hline 26 & M32 & 3 boyutlu modelleme dersinde başarılı olmak için elimden geleni yaparım. & & & \\
\hline 27 & M33 & 3 boyutlu modelleme ile ilgili bilgilerimi arttırmak için ayrıca bir eğitim almayı isterim. & & & \\
\hline 28 & M34 & 3 boyutlu modelleme alanında uzman olana kadar çalışmak istiyorum. & & & \\
\hline 29 & M36 & Meslek hayatım için 3 boyutlu modelleme bilgisi gerekli değildir. & & & \\
\hline 30 & M37 & 3 boyutlu modelleme dersi en zor dersler arasındadır. & & & \\
\hline
\end{tabular}

\section{Copyright (C) JCER}

JCER's Publication Ethics and Publication Malpractice Statement are based, in large part, on the guidelines and standards developed by the Committee on Publication Ethics (COPE). This article is available under Creative Commons CC-BY 4.0 license (https://creativecommons.org/licenses/by/4.0/) 